\title{
A New Solution for Sea Wave Energy Harvesting, the Proposal of an Ironless Linear Generator
}

\author{
Domenico Curto * ${ }^{\circ}$, Alessia Viola, Vincenzo Franzitta $₫$, Marco Trapanese $₫$ and Fabio Cardona \\ Department of Engineering, University of Palermo, 90128 Palermo, Italy; alessia.viola@deim.unipa.it (A.V.); \\ franzitta@dream.unipa.it (V.F.); marco.trapanese@unipa.it (M.T.); fabio.cardona@unipa.it (F.C.) \\ * Correspondence: domenico.curto@deim.unipa.it
}

Received: 2 January 2020; Accepted: 1 February 2020; Published: 3 February 2020

\begin{abstract}
The paper investigates an innovative ironless linear generator, installable inside a wave energy converter, in order to produce electricity from sea waves. This energy source is considered strategic for the future, especially in small islands; however, this technology is still far from the commercial phase. Considering the wave energy potential of the Mediterranean Sea, a first prototype of the electrical linear generator was realized at the Department of Engineering of Palermo University. This machine can be run by a two-floating buoys system, able to produce a linear vertical motion. The main goal of this paper is the investigation of the advantages and the disadvantages of the utilization of steel materials to realize the stator of linear generators. Thus, starting from the prototype, the authors analyzed the effects produced by the replacement of steel in the stator with a non-magnetic material. For comparison, the authors evaluated the amplitude of no-load voltages, using a three-phase connection scheme, and the amplitude of the magnetic force produced by the interaction of magnets with the stator. Both aspects were evaluated through numerical simulations and mathematical models.
\end{abstract}

Keywords: sea wave; point absorber; linear generator; energy harvesting

\section{Introduction}

Sustainable electricity generation is nowadays a fundamental priority for industrialized countries [1]. Several technologies have been developed for the exploitation of Renewable Energy Sources (RES), like hydro, wind, and solar. Nevertheless, around the world the share of RES in electricity generation continues to be low, with a strong dependence from fossil fuels, that are responsible for greenhouse gases (GHG) emissions, and consequently global warming [2]. To clarify the relevance, a recent analysis indicates that electricity generation is responsible for the emission of two-thirds of all anthropogenic GHG production [3].

In regards to the electrical energy sector, in 2018 the world average share of electricity production from RES was equal to $25.60 \%$, with the following local shares: $32.72 \%$ in the European Union, $23.78 \%$ in North America, 58.49\% in Latin America (thanks to the relevant contribution from hydropower), $22.36 \%$ in Asia, 28.96\% Oceania, 17.78\% Africa, and 2.11\% Middle East [4]. Based on data reported in [5], Figure 1 shows the progressive increase of the installed power capacity from RES. In detail, the global power capacity has been increasing with an average annual growth rate of $8.33 \%$, achieving the value of $2351 \mathrm{GW}$ at the end of 2018 [5]. From 2015, solar photovoltaic (PV) has been the technology preferred for new installations. Indeed, solar PV represented about $55.3 \%$ (94.76 GW) of newly installed power in 2018, while wind and hydropower accounted for most of the remainder, contributing for $28.6 \%(49.10 \mathrm{GW})$ and $12.5 \%(21.35 \mathrm{GW})$, respectively [5]. 


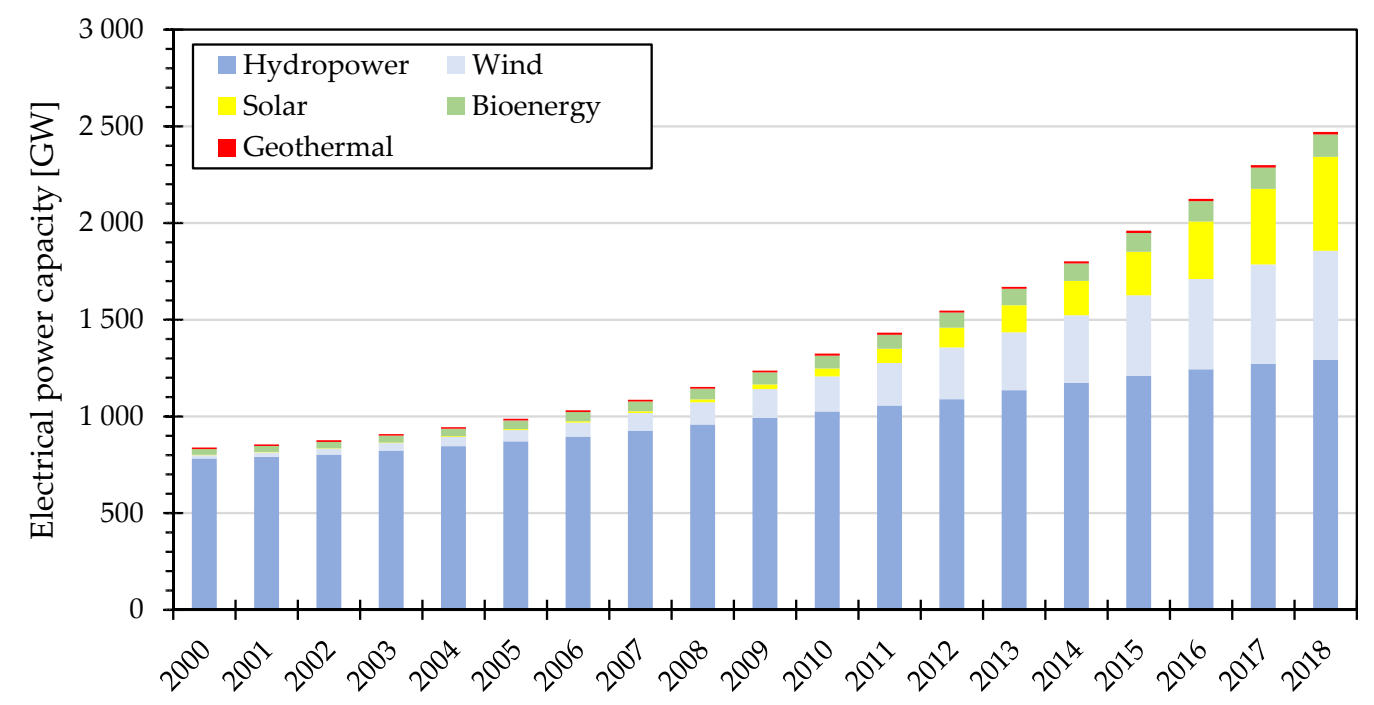

Figure 1. World electricity capacity by renewable energy sources for 2000-2018 (based on data in [5]).

Concerning the utilization of RES, several technologies are commercial mature, such as wind and hydro turbines, and solar photovoltaic panels [6].

There are other energy sources that are practically not exploited, such as sea wave [7]. In this case, the idea is based on the exploitation of the oscillating motion produced by the sea in order to generate electricity. Although there are no mature technologies for its utilization, several researchers affirm that, in a short period, sea wave will give important support to the energy sector [8]. In particular, the main contribution will be concentrated in small islands [9]. Similar to other renewable sources, the diffusion of devices supplied by sea wave could create local job opportunities [10].

Sea wave is an indirect consequence of solar radiation. Indeed, the energy emitted by the sun warms the earth's surface, causing wind generation. In turn, wind interacts with the water surface and produces sea waves; therefore, a very small ratio of solar energy is finally converted in sea wave energy.

Just to quantify the energy conversion chain, it is estimated that the earth is exposed to a total radiation of $174 \mathrm{PW}$, of which only $78 \mathrm{PW}$ (corresponding to 683,280 $\mathrm{PWh} / \mathrm{y}$ ) reaches the earth's surface [11]. About 1.2 PW (10512 PWh/y) is converted in wind energy. In regard to sea wave, a recent report underlines that the total theoretical energy potential is about $32 \mathrm{PWh} / \mathrm{y}$, not evenly distributed throughout the world [8].

Although the total energy potential of sea wave seems small in comparison with the availability of solar radiation, the exploitation of this new renewable energy source represents a valid opportunity, thanks to several peculiarities: [12]

- The power density is higher in comparison with other RES, therefore these power plants require a lower extension;

- Sea wave is more regular than wind, increasing the annual operative hours of these systems;

- The visual impact is lower than other RES technologies, since most devices for sea wave exploitation are located close to sea level;

- The energy potential is still enough to meet a significant portion of the world's energy demand (26.59 PWh/y in 2018) [4].

Focusing on sea wave, several hot spots, i.e., regions with high values of wave energy potential, can be identified around the world. As an example, the southern part of Australia, Africa, and America are exposed to the greatest values of wave energy potential. More moderate areas are located between the USA, Canada, and Japan in the Pacific Ocean, and between the European Union, Greenland, USA, and Canada in the Atlantic Ocean. Unfortunately, all of these areas are also affected by extreme bad weather conditions that are normally related to the high level of energy potential. In this case, the 
utilization of this energy source is more complex, since the device must also be sized to resist in the worst weather conditions $[13,14]$.

In this context, the term Wave Energy Converters (WEC) is referred to devices that are able to extract energy from sea waves, and produce electrical energy or other useful energy output [15].

Many types of WEC have been proposed over time. These systems can be classified by using different criteria, such as the position with respect to the coastline or the sea level, the average size, the orientation with respect to the direction of wave propagation or, finally, the working principle. The following terms are commonly used to identify specific layout of WEC [16]:

- Attenuator is generally composed by a floating device oriented along the wave direction. This kind of system rides the crest of waves in order to produce a relative motion between the sections of which it is composed, running the internal energy converters [17].

- Point absorber is a system characterized by axial symmetry, in order to work independently of wave direction [18].

- Oscillating wave surge converters are designed for a nearshore application. Indeed, the system is composed by a barrier, fixed on a seabed by a hinge, in order to oscillate as a pendulum, according to the wave motion in shallow water [19].

- Submerged pressure differential devices are installed on a seabed. They are composed by a fixed part and a movable one. The variation of the hydrostatic pressure on the device generates a vertical motion, usable to activate linear generators or hydraulic pumps [20].

- Overtopping systems are composed of a water reservoir above sea level. By using a ramp, the kinetic energy of waves is converted into potential, refilling the reservoir. The accumulated water is used to run a low-head water turbine [21].

- Rotating mass systems are equipped with big masses installed inside with an eccentric. The oscillation produced by waves (mainly pitch and roll) induces the rotation of the masses, accumulating kinetic energy usable by rotary generator to produce electrical energy [22].

Attenuators are typically realized by connecting several cylindrical buoys. Sea wave produces relative motions on the junctions, running fluid pumps [23]. Consequently, this kind of energy is converted into electricity through hydraulic expanders and alternators [24].

As introduced above, the main feature of point absorbers is the ability to work independently of the wave direction. A possible solution is represented by a symmetrical buoy, located in open sea. The buoy is used to collect the mechanical energy of sea wave and produce a vertical motion in order to run the power take-off installed on the sea bed [25]. As an example, the AquaBuOY system is equipped with a floating buoy and an hydraulic pump system [26].

With the target of oceanic wave exploitation, some systems are designed to be installed completely under sea level. The "Archimede Wave Swing" is an example of a submerged pressure differential system [27]. In detail, the device comprises an air-filled chamber, which is alternatively compressed and expanded by the variation of hydrostatic pressure on the device.

Another approach for the exploitation of sea wave is represented by overtopping systems, of which "Wave Dragon" is an example [28]. The system is equipped with a floating water reservoir. A ramp is used to convey sea wave inside the reservoir. In this way, the wave's kinetic energy is accumulated as potential energy. A low head hydraulic turbine is used to produce electricity, returning water to the ocean.

In this context, an interesting solution is represented by point absorbers, equipped with linear electrical generators, since these components are able to produce electrical energy directly from a linear motion, simplifying the energy conversion chain [25].

With this purpose, the Department of Engineering of Palermo University is currently investigating new solutions for the exploitation of sea wave energy potential, considering the Mediterranean Sea as a potential energy source to cover a part of the local energy demand in small islands [29-31]. 
A first prototype of a linear generator was realized and tested in the laboratory. This system is described in the following sections. With the aim to optimize this technology, the authors suggest a revolutionary approach, i.e., the realization of an ironless system. The main goal is the removal of the cogging force in order to increase the range of the exploitable wave height, maximizing the annual energy production. In detail, the solution is represented by the replacement of iron stator, with another one based on non-magnetic materials.

At the same time, the removal of iron from the stator could reduce the internal power loss from the generator by eliminating eddy currents inside the stator [32].

The analysis of the cogging force is an important aspect for linear generators. A detailed computation of a magnetic field is consequently required in the study of electromechanical devices [33]. The cogging force usually rises in the linear generator because of irregular air gap magnetic permeance.

Indeed, the teeth-slots alternation and the finite stator length create variations in the air gap and consequently on the local distribution of the magnetic field. Thus, the cogging force generates serious mechanical vibrations, which reduce the electricity production, especially under the condition of limited wave height. Furthermore, the speed fluctuation induced by the cogging force could degrade the quality of output power [34].

However, from a theoretical point of view, the removal of the iron from the stator produces a significative reduction of power output, due to the reduction of magnetic flux through the stator windings [35].

In order to quantify all these effects, numerical simulations have been performed on a specific Finite Element Method (FEM) tool, in order to compare two different case studies: the linear generator, described below, equipped with an iron stator and with an ironless stator. In detail, the authors investigate the no-load voltages produced in the output coils and the cogging force generated by the magnetic interaction between the stator and the translator.

\subsection{Background on Linear Generator Topology}

As previously discussed, a possible classification of WEC is based on the specific technologies installed inside the system for the conversion of mechanical energy of sea wave into electrical energy [36]. Clearly, this choice deeply influences the designing step of WEC.

In this context, a promising solution suggests the adoption of linear generators, thanks to their peculiarity of converting directly a linear input motion into electrical energy. In this way, the energy conversion chain is drastically simplified using a limited number of components [37]. Other, more widespread systems, instead, firstly store the sea wave energy, pressurizing fluids through piston pumps, and then convert this energy into electrical using alternators driven by hydraulic turbines or volumetric expanders [38]. Thanks to the "direct-drive" solution (i.e., the direct coupling of the floating buoy's velocity and force to the generator), linear generators are currently a research topic [39]. In particular, an interesting solution is represented by Permanent Magnets (PM) linear generators, as the simplified topology of these machines [40].

Generally, linear generators are made up by two parts: stator (an iron fixed part) and translator (moving part). An example is depicted in Figure 2, where the stator is sectioned in order to show the position of coils. 


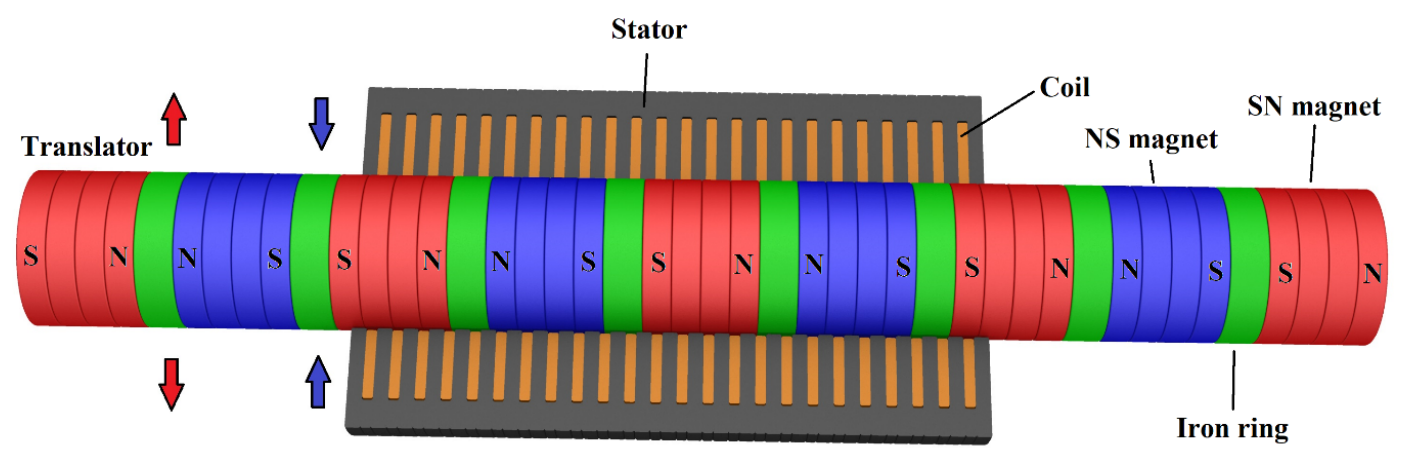

Figure 2. Permanent Magnet generator's framework.

A detailed classification of linear generators is reported in [41]. Considering the shape of the generator, the following definition are adopted:

- Structure of generator: flat structure-a generator having a planar symmetry, such as the system proposed in the paper (see the following section); or tubular structure-if stator and translator have an axial symmetry, such as two coaxial cylinders (see Figure 2).

- Length of translator in comparison with the stator: long translator-if the translator is longer than the stator; or a short translator, in the other case.

- Position of translator in comparison with the stator: external translator-if the translator moves in a region outside the stator; or internal translator-if the translator is installed inside the stator region.

- Place where the permanent magnets are installed: stator PM-if magnets are installed on the stator; or translator $\mathrm{PM}$ - if magnets are located on the translator.

Tubular generators are investigated deeper in literature, since the analogy with electric actuators [42]. Considering a tubular generator, four configurations are usually adopted to install PM on the translators: radial, axial, Halbach and quasi-Halbach. In the first case, PM are magnetized along the radius, alternating the magnetic poles (see Figure 3a). In the axial configuration, PM are magnetized along the same axis of the translator (see Figure $3 b$ ). In the Halbach scheme, PM are magnetized along the axis, but are oriented in order to oppose the same poles (see Figure 3c). To assemble the stator, a ferromagnetic material is installed between the magnets. In effect, the resulting magnetic field is oriented on the radial direction. Finally, in the quasi-Halbach configuration, axial and radial magnets are alternated in order to minimize the magnetic field inside the translator and maximize the outside (see Figure 3d).

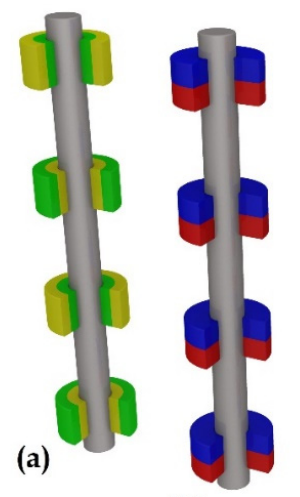

(b)

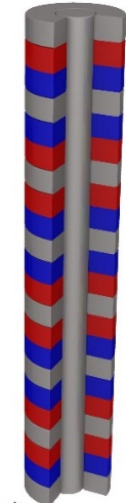

(c)

(d)

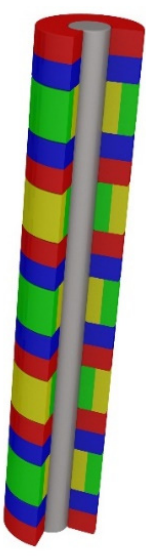

Figure 3. Different magnetization schemes: (a) radial, (b) axial, (c) Halbach, (d) quasi-Halbach. 
Considering the position of windings in comparison with the translator motion, linear generators are classified as transverse flux, if the flux path through coils is perpendicular to the translator motion, or longitudinal flux, if the flux path is parallel. Pertaining to the material adopted in the stator, linear generators are defined as iron-cored, if the stator is realized with a ferromagnetic material or air-cored, otherwise. Finally, in literature, another kind of generator is investigated: linear switched reluctance generator. In this case, the magnetization is realized by coils, which require a control system function of the translator position [42].

There are advantages when permanent magnets are installed in the moving part of the machine: the generation of the magnetic induction field without the adoption of excitation current allows the removal of the entire excitation circuit, including conductors and sliding contacts where joule losses are concentrated [41].

The main drawbacks of these generators are: high value of the cogging force and the cost of magnets, especially in the case of rare-earth magnets, such as samarium cobalt ( $\mathrm{SmCo}$ ) or neodymium iron boron (NdFeB) [43].

The cogging force is generated by the interactions between the magnets and the slotted iron structure. There are two origins to this phenomenon: the alternance of teeth and slots along the stator and the finite length of this component. The cogging force produces a pulsating force ripple, resulting in vibrations and acoustic noise.

This phenomenon is also common in rotary machines, where the reduction of cogging torque is investigated to maximize the energy performances [44-46]. In this case, geometric parameters are usually investigated, such us the introduction of a skewing angle for the stator slots along the main axis or permanent magnets on the rotor [47], the adoption of particular numbers for the realization of stator and rotor teeth [48], and the optimization of the shape of stator teeth [45].

In case of rotary machines, cogging torque is essentially related to the alternance of teeth and slots in the stator, during the rotation of the rotor [44]. In a similar way, the alternance of teeth and slots produces also a cogging force in linear machines [49]. In addition, linear machines are also affected by the "end effect" in the generation of the cogging force [50]. Indeed, in rotary machines, all permanent magnets are located inside the stator regions, whereas in linear machines, it is possible that magnets are forced to enter and exit the region delimited by the stator, especially if the long translator configuration is adopted. In this case a strong interaction between magnets and stator is realized [51].

Therefore, solutions normally proposed in rotary machines solve only a part of the problem pertaining to the cogging force in case of linear machines [52]. To solve the end effect, specific solutions should be adopted, like the optimization of the shape of the auxiliary teeth (the first one and the last one) in the stator, in order to minimize this phenomenon [50].

An alternative solution is represented by the utilization of non-magnetic materials for the realization of the stator. As introduced before, this phenomenon is absent in case of air-core linear generators, for this reason, the investigation of this solution appears interesting to the authors.

For this reason, the replacement of the iron stator with a non-magnetic one is investigated in this paper. To compare, the authors considered an iron-core prototype realized in previous studies at the laboratory of the Engineering Department of Palermo University [31]. By using an FEM tool, the replacement of the iron-stator with a non-magnetic one is investigated, by considering the effects on the no-load voltage trends and on the cogging force.

In the next section, the iron-core prototype is first described; in the following section, a comparison with an air-core device, having the same shape, is reported on. 


\section{Materials and Methods}

\subsection{The Prototype}

In order to exploit the wave energy potential in the Mediterranean Sea, the Department of Engineering of Palermo University designed a first prototype of an electrical linear generator [53]. This machine can be installed inside a two-floating buoyage system, in order to exploit its vertical motion.

A flat structure configuration was adopted to simplify the realization of the device, because it is possible to adopt greater processing tolerances, and it is easy to assemble by hand. These aspects are relevant during tests in order to replace components and change some parameters [54].

Like other linear generators, this prototype is composed of two parts: the stator and the translator. The first part is composed by laminated sheets of AISI 1008, stacked vertically. The lamination is introduced to reduce the eddy currents inside the device and increase the energy efficiency.

Since the prototype is a flat structured machine, the stator is split in two elements, each one having the following sizes [55]: $971 \mathrm{~mm}$ (length), $65 \mathrm{~mm}$ (height), and $60 \mathrm{~mm}$ (width). Each part has 39 slots used to install 36 coils, where the electrical power is produced. Each coil comprises 375 turns of enameled copper, with the average sizes of $85 \mathrm{~mm}$ (width) and $125 \mathrm{~mm}$ (height). The stator is assembled using threaded bars and bolts, as shown in Figure 4. Considering all components, the stator of prototype has a mass equal to $74.5 \mathrm{~kg}$, of which $45.7 \mathrm{~kg}$ are due to the AISI 1008 used in the stator.

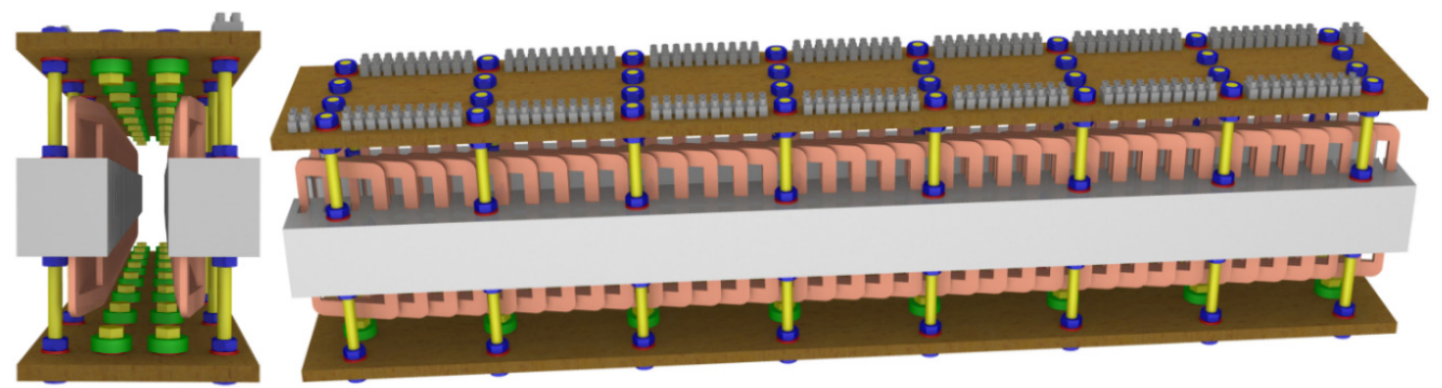

Figure 4. Lateral and front views of stator.

The generation of the magnetic field is entrusted to the permanent magnets installed on the translator, i.e., the moving part of the linear generator. As shown in Figure 5a, magnets are installed with a skewing angle equal to $17^{\circ}$ around the axis perpendicular to the translator. As explained in the introduction, the skewing of PM or alternatively of stator slots, is a common approach to minimize the cogging torque in rotary machine. The same idea was adopted in the prototype in order to minimize the cogging force associated with the alternance of teeth and slots.

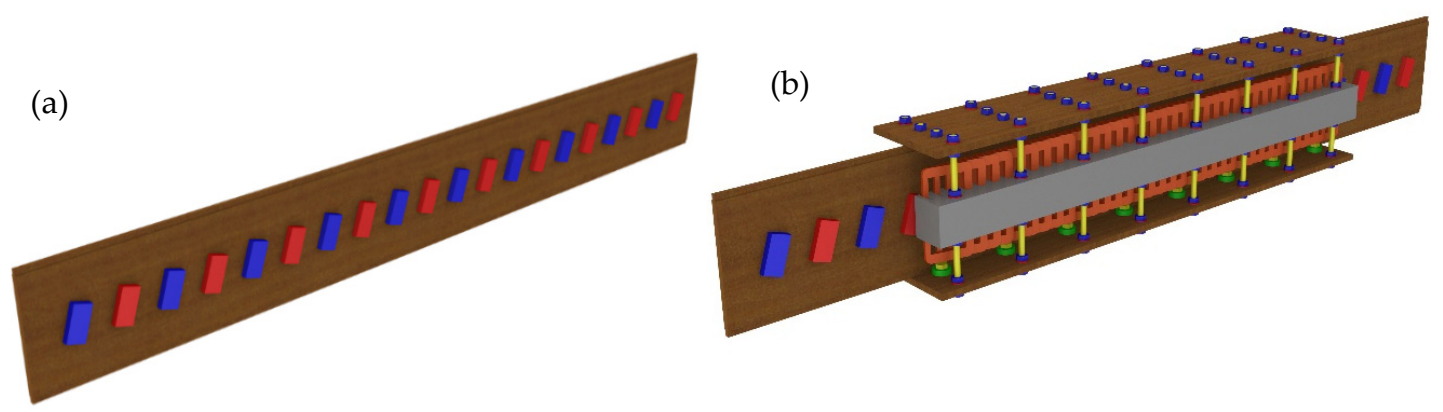

Figure 5. A translator view (a) and a 3D view of the entire system (b). 
The translator is currently made with a bakelite table, having the sizes of $1600 \mathrm{~mm}$ (length), $205 \mathrm{~mm}$ (height), and $12 \mathrm{~mm}$ (width). The translator has 40 slots (20 on each side), in order to install the same number of permanent magnets, alternating the poles along the major dimension, as shown in Figure 6. Magnets are glued to the support, and the magnetic attraction between the pairs of magnets helps to maintain their position.

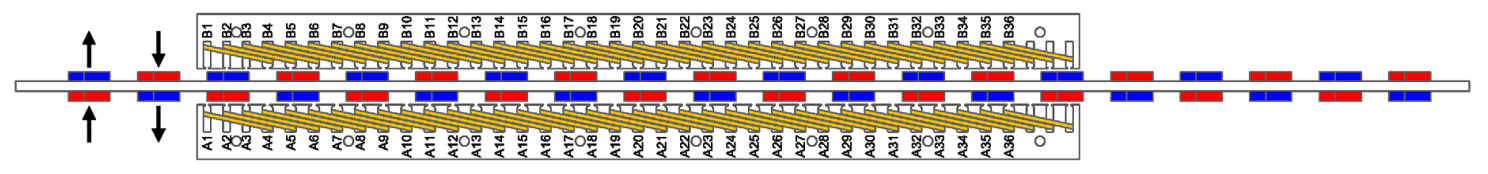

Figure 6. Magnetization of PM in the translator and position of coils in the stator.

The magnetization of PM is perpendicular to the motion of the translator, in order to maximize the magnetic flux crossing the coils installed in the stator. In this configuration, the translator has a mass equal to $13 \mathrm{~kg}$, of which $8.2 \mathrm{~kg}$ are due to magnets.

More details about magnets are reported in Table 1 . In comparison with the stator, the translator is longer, so the device is designed, considering that magnets enter and exit through the region, delimited by stator during the motion of translator.

Table 1. Datasheet of permanent magnets [56].

\begin{tabular}{cc}
\hline Article ID. & Q60-30-15-N \\
\hline Material & NdFeB \\
Shape & block \\
Size & $60 \times 30 \times 15 \mathrm{~mm}$ \\
Pole faces & $60 \times 30 \mathrm{~mm}$ \\
Tolerance & $\pm 0.1 \mathrm{~mm}$ \\
Coating & Nickel-plated $(\mathrm{Ni}-\mathrm{Cu}-\mathrm{Ni})$ \\
Manufacturing method & Sintered \\
Direction of magnetization & Axis $15 \mathrm{~mm}$ \\
Magnetization & $\mathrm{N} 40$ \\
Strength & Approx. $56 \mathrm{~kg}(549 \mathrm{~N})$ \\
Max working temperature & $310^{\circ} \mathrm{C}$ \\
Curie temperature & $205.2 \mathrm{~g}$ \\
Weight & $12,600-12,900 \mathrm{G}, 1026-1.29 \mathrm{~T}$ \\
Residual magnetism Br & $10.5-12.0 \mathrm{kOe}, 860-955 \mathrm{kA} / \mathrm{m}$ \\
Coercive field strength bHc & $\geq 12 \mathrm{kOe}, \geq 955 \mathrm{kA} / \mathrm{m}$ \\
Coercive field strength iHc & $38-40 \mathrm{MGOe}, 303-318 \mathrm{~kJ} / \mathrm{m}^{3}$ \\
Energy product (BxH)max &
\end{tabular}

\subsection{Numerical Approach}

The analysis has been realized by using a specific FEM software for the investigation of electrical machines. FEM is a numerical approach for finding approximate solutions to boundary value problems modelled by partial differential equations. It is useful for problems with complicated geometries and material properties, where analytical solutions are difficult or even impossible to obtain. The finite element method converts partial differential equations into a set of algebraic equations, which are easy to solve. The simulations have been carried out using the sequence reported in Figure 7. 


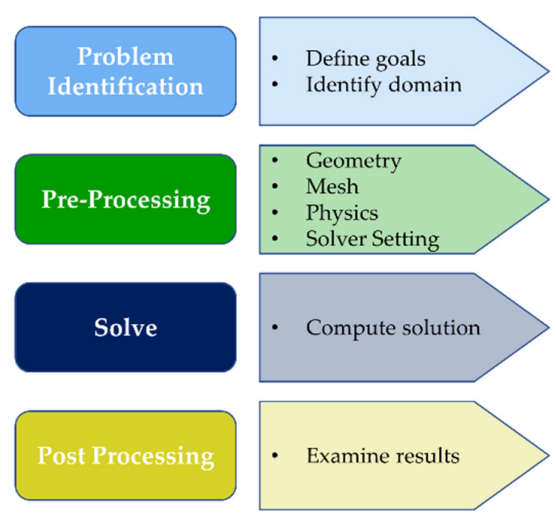

Figure 7. FEM simulation's environment.

In this case study, the evaluation of cogging force and no-load voltages are estimated using two different simulation environments; in detail, the solvers used are:

- Magneto-static solution type: a static magnetic field is solved resulting from permanent magnets and it represents a no time variable study. The definition of magnetic properties of materials is essential. This environment is useful to analyse the cogging force.

- Transient solution type: a simulation that computes the time varying magnetic and electric fields. This is a time domain solver, necessary to analyse the induced voltage in the output coils, because of the time variation of the magnetic field, produced by the translation of permanent magnets through the stator.

Following Maxwell's equations [57], are solved with the magneto-static solver:

$$
\begin{gathered}
\nabla \times \vec{H}=\vec{J} \\
\nabla \cdot \vec{B}=0 \\
\vec{B}=\mu_{0}(\vec{H}+\vec{M})=\mu_{0} \mu_{r} \vec{H}+\mu_{0} \vec{M}_{p}
\end{gathered}
$$

where $\vec{H}$ is the magnetic field strength, $\vec{B}$ the magnetic flux density, $\vec{J}$ the conduction current density, $\vec{M}$ the magnetization of material, $\vec{M}_{p}$ the permanent magnetization of material, $\mu_{0}$ the permeability of vacuum and $\mu_{r}$ the relative permeability of the material. As for the transient solver, the tool resolves Equation (2):

$$
\begin{gathered}
\nabla \times \frac{1}{\sigma} \nabla \times H+\frac{\partial B}{\partial t}=o \\
\nabla \cdot \vec{B}=0 \\
-\nabla \cdot\left(\varepsilon \nabla \frac{\partial \Phi}{\partial t}\right)-\nabla \cdot(\sigma \nabla \Phi)=0
\end{gathered}
$$

In the next section, the authors report the results obtained by using a magneto-static solution type to calculate the cogging force, and a transient solution type to evaluate the no-load voltage trends. In both cases, the FEM tool was set to carry out 3D analyses because of the geometric properties of the prototype, such as the skewing of permanent magnets.

\section{Results}

As introduced above, the main goal of this paper is the evaluation of the advantages and the disadvantages due to the utilization of steel materials to build the stator of linear generators.

Therefore, starting from the prototype depicted in the previous sections, the authors quantified the effects produced by the replacement of iron from the stator with a non-magnetic material. As a comparison, the authors analyzed the following main phenomena:

- No-load voltage trends, considering a three-phase connection of coils; 
- Magnetic force produced by the interaction of magnets, with the stator in a magneto-static condition.

\subsection{No-Load Voltages}

The prototype is designed as a three-phase machine. The step between two adjacent coils is equal to one sixth of the step between two magnets with the same magnetic pole.

In this condition, considering a block with six adjacent coils, and selecting one of them, there is always one that produces a voltage trend in phase opposition for geometrical reasons. Therefore, inverting the polarity of half of the coils, a possible three-phase scheme of the connection is proposed in Figure 8.

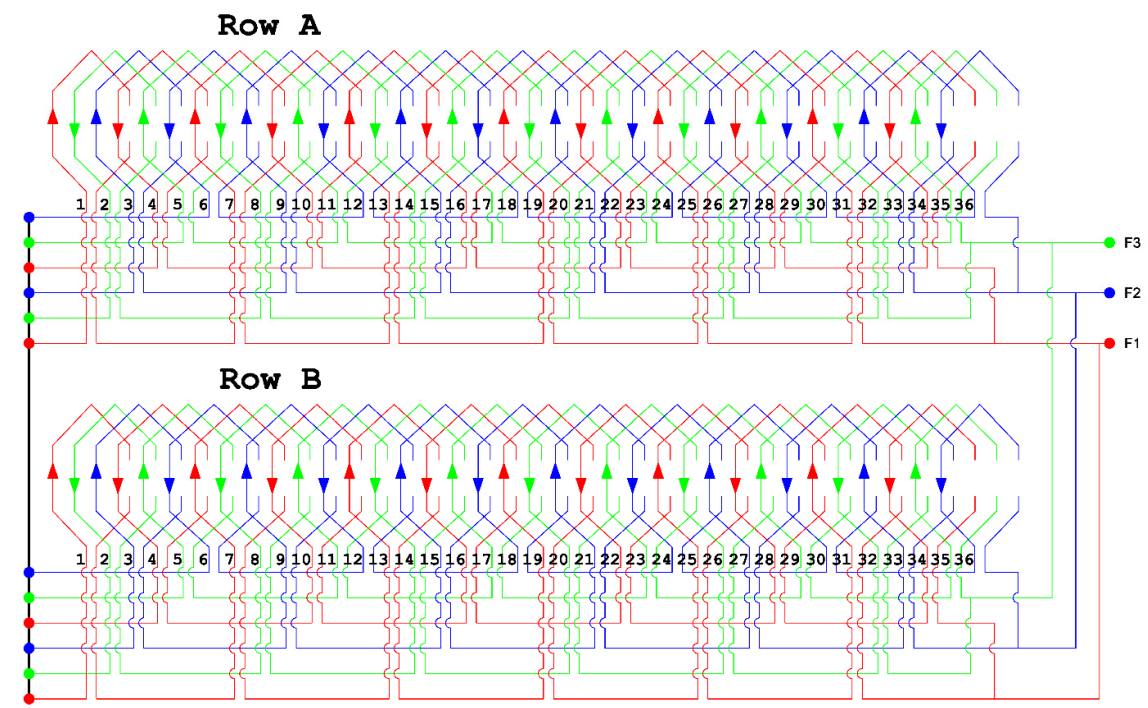

Figure 8. Three-phase connection of the generator.

Since the generator is a bilateral machine, two rows of coils are drawn. Overall, each phase includes four lines, each one comprising six coils connected in series, with a total of 24 coils for each phase.

Assuming the connection scheme proposed in Figure 8, the authors simulated the no-load voltage trends produced by the prototype, fixing the speed of the translator to $1 \mathrm{~m} / \mathrm{s}$. The results are reported in Figure 9. These values are confirmed by previous experimental tests on a full-scale prototype in the laboratory $[31,53]$.

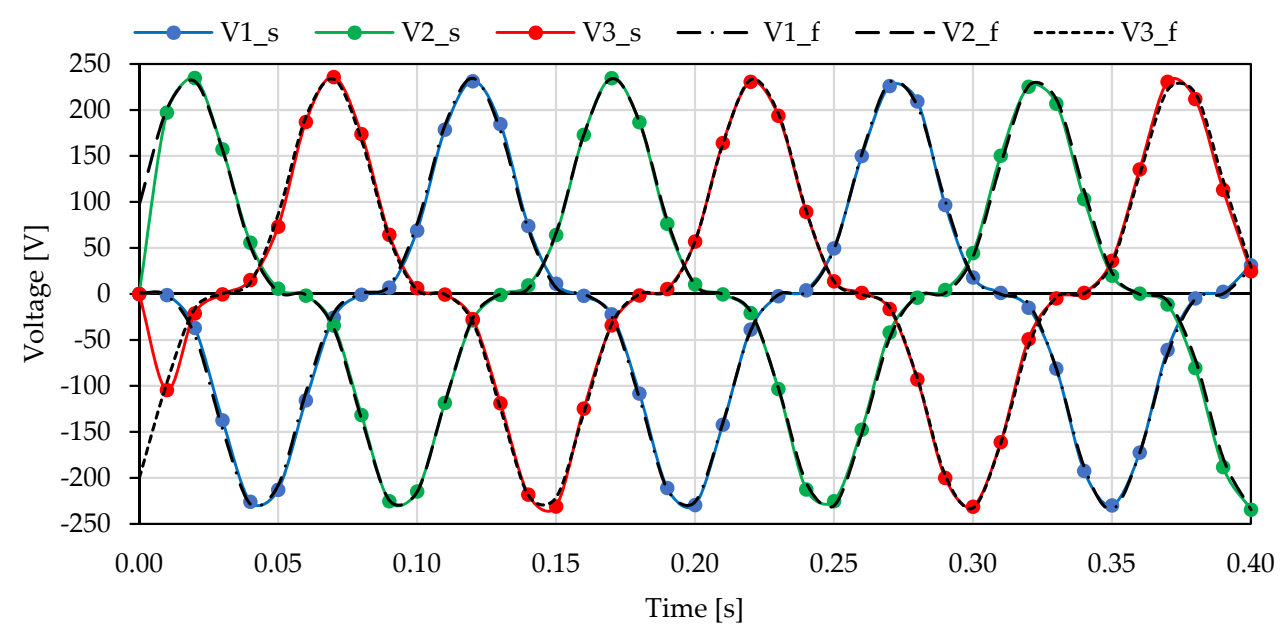

Figure 9. No-load voltages produced by prototype, with a translator speed equal to $1 \mathrm{~m} / \mathrm{s}$. 
The graph also reports the Fourier series approximation, trimmed to the third harmonic, according to Equation (3). All parameters are reported in Table 2.

$$
V_{i, f}(t)=A_{1} \sin \left[\omega t+\varphi_{1}-\frac{2}{3} \pi(i-1)\right]+A_{3} \sin \left(3 \omega t+\varphi_{3}\right)
$$

Table 2. Fourier approximation of no-load voltages produced by prototype.

\begin{tabular}{cccc}
\hline Parameter & Symbol & Value & Unit \\
\hline First harmonic amplitude & $\mathrm{A}_{1}$ & 175.24 & $\mathrm{~V}$ \\
Third harmonic amplitude & $\mathrm{A}_{3}$ & 59.24 & $\mathrm{~V}$ \\
First harmonic phase & $\varphi_{1}$ & 2.941 & $\mathrm{rad}$ \\
Third harmonic phase & $\varphi_{3}$ & -0.607 & $\mathrm{rad}$ \\
Angular frequency & $\omega$ & 41.07 & $\mathrm{rad} / \mathrm{s}$ \\
\hline
\end{tabular}

Equation (3) represents a simplified form of a more general equation, used by the authors for the evaluation of no-load voltage trends in the case of a general motion, considering the trend of the translator motion as input:

$$
V_{i, f}(t)=\frac{A_{1}}{v_{0}} \frac{d x(t)}{d t} \sin \left[k x(t)+\varphi_{1}-\frac{2}{3} \pi(i-1)\right]+\frac{A_{3}}{v_{0}} \frac{d x(t)}{d t} \sin \left[3 k x(t)+\varphi_{3}\right]
$$

In detail, in Equation (4) $x(t)$ represents the time function of the translator position. The other parameters introduced are: the speed $v_{0}$ used in the reference test with a linear constant motion (equal to $1 \mathrm{~m} / \mathrm{s}$ ) and the wavenumber $k$ of the generator, that is determined by Equation (5), considering the distance $\lambda$ between two magnets having the same pole.

$$
k=\frac{2 \pi}{\lambda}
$$

If the translator is moved with a constant linear motion, in general the angular pulsation introduced in Equation (4) is linearly related to the wavenumber of the generator, by Equation (6):

$$
\omega=k v=\frac{2 \pi}{\lambda} v
$$

Focusing the attention on Figure 9, it is possible to observe the presence of the third harmonic, which increases the value of the peak and the time step when the voltage trends are close to zero. In general, the third harmonic must be avoided, since this component generates a pulsating production of electrical power, vibrations and noises in the machine.

Another FEM simulation was performed considering the replacement of AISI 1008 from the stator with a non-magnetic material, and evaluating the no-load voltage trends, without changing any geometrical parameter of the prototype. The same constant speed $(1 \mathrm{~m} / \mathrm{s})$ is imposed to the translator motion. The results of this analysis are reported in Figure 10. 


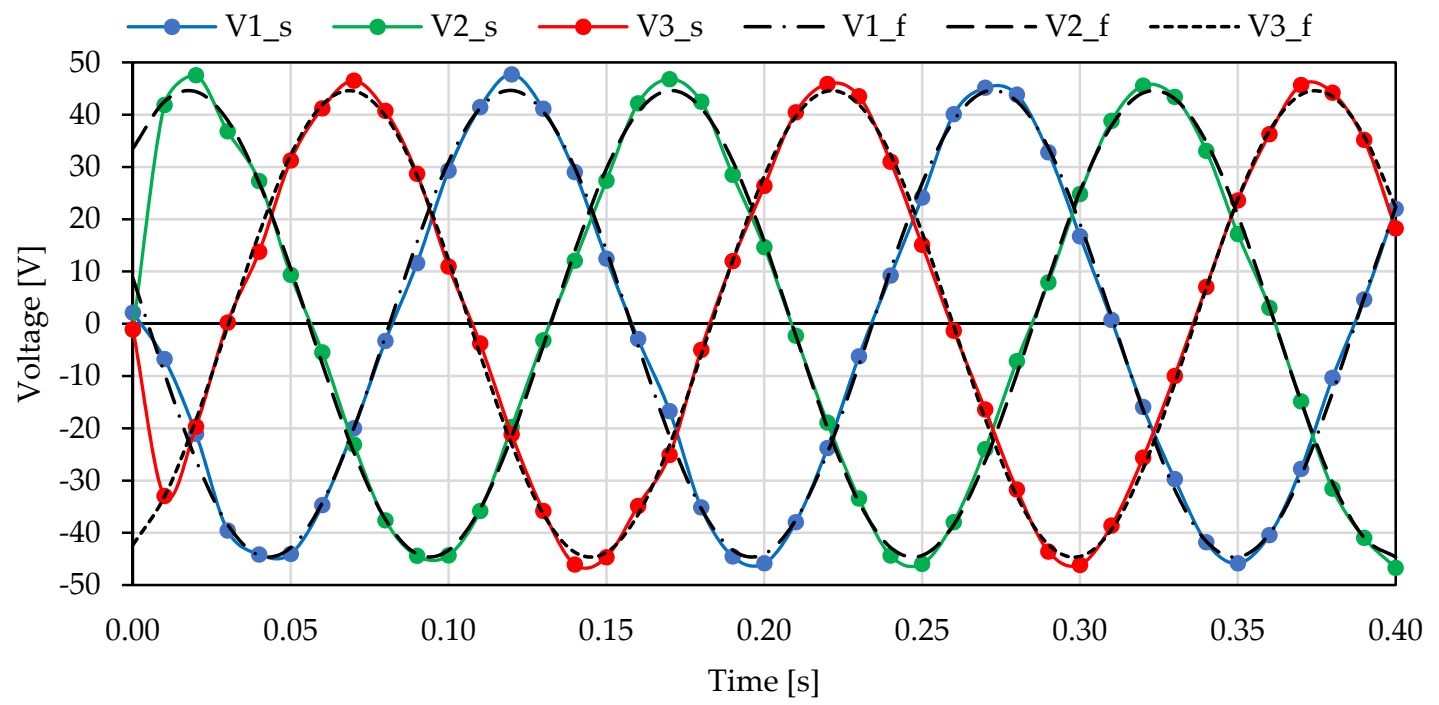

Figure 10. No-load voltages, considering a non-magnetic material in the stator.

The Fourier series approximation was evaluated. In this case, the first harmonic is enough to describe the no-load voltage trends, thus, Equation (3) is simplified in Equation (7).

$$
V_{i, f}(t)=A_{1} \sin \left[\omega t+\varphi_{1}-\frac{2}{3} \pi(i-1)\right]
$$

The amplitude of first harmonic is the only parameter affected by a significant variation, as reported in Table 3.

Table 3. Fourier approximation of no-load voltages produced by prototype.

\begin{tabular}{cccc}
\hline Parameter & Symbol & Value & Unit \\
\hline First harmonic amplitude & $\mathrm{A}_{1}$ & 44.65 & $\mathrm{~V}$ \\
First harmonic phase & $\varphi_{1}$ & 2.946 & $\mathrm{rad}$ \\
Angular frequency & $\omega$ & 41.07 & $\mathrm{rad} / \mathrm{s}$ \\
\hline
\end{tabular}

As shown in Figure 11, the magnetic flux through coils is drastically reduced, for this reason the no load voltage trends assume lower values in the case of iron-less stator.
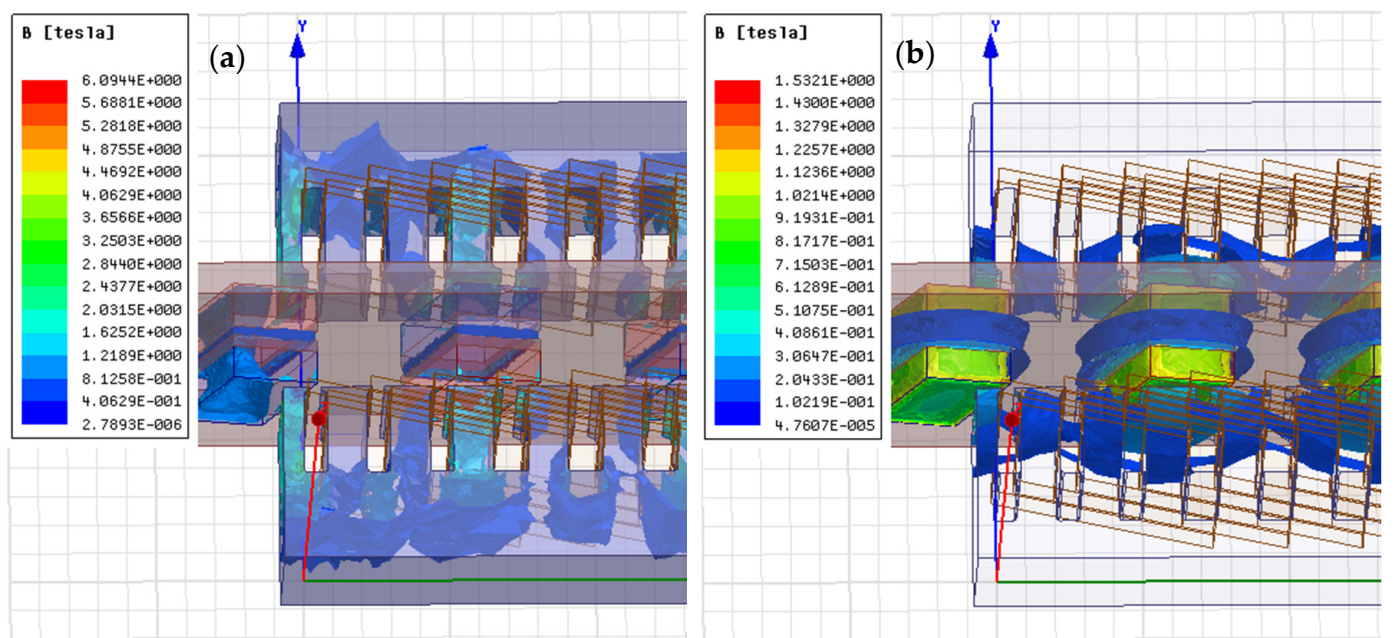

Figure 11. Comparison of magnetic field distribution in case of iron-core (a) and air-core stators (b). 
Including the effect of the third harmonic in the first case, the comparison of Figures 9 and 10 reveals a significant reduction of the peak of voltages, from 234.5 to $44.65 \mathrm{~V}$, with a ratio of about 5.25:1. As introduced above, the third harmonic produces several problems in the electrical machine. Furthermore, the linear generator is designed to exploit a variable linear input. The amplitude and the angular frequency of voltages change according to the speed of the translator; thus, an electronic power converter is required to stabilize the electrical power output. In order to avoid the generation of the third harmonic, two techniques can be adopted:

- Use other schemes of connection for coils;

- Not connect the star center of generator to load.

In the first case, the authors considered the scheme depicted in Figure 12. The system is connected in order to obtain two lines for phase, each one having 12 coils in series. The adjacent coils are connected two-by-two in series.

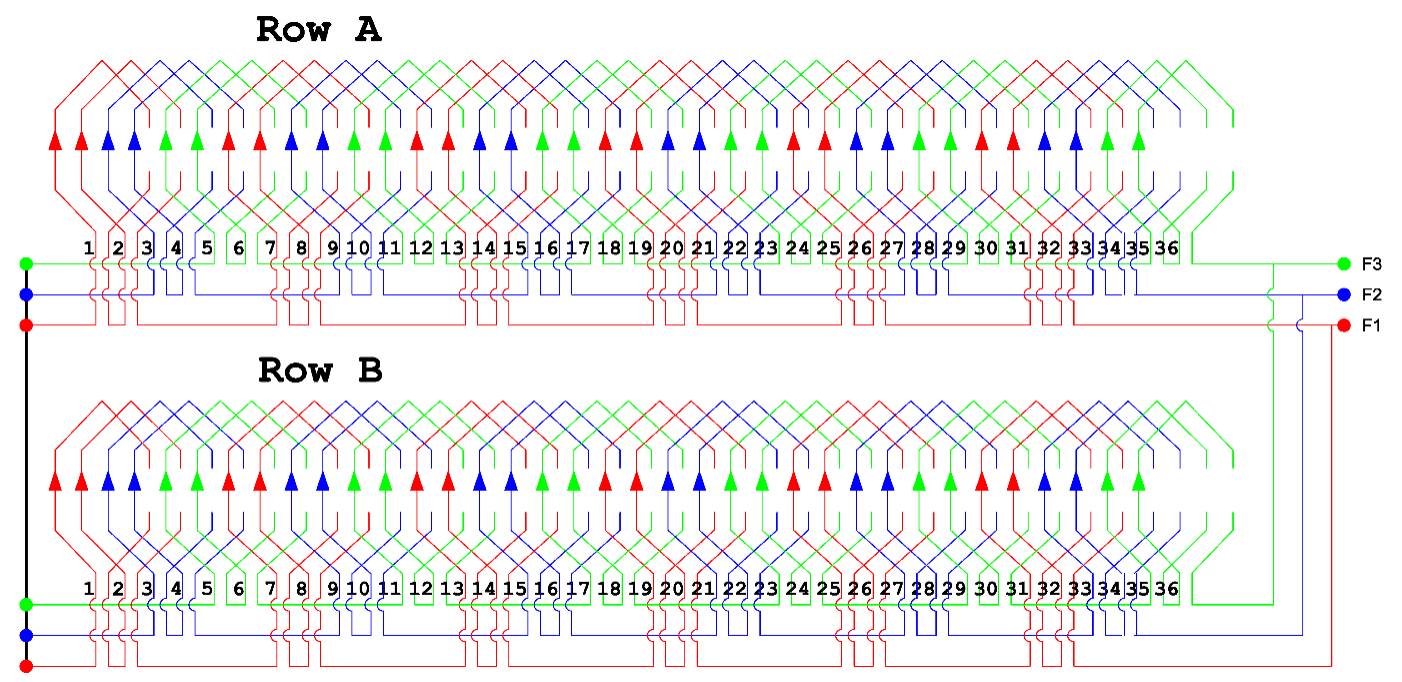

Figure 12. Alternative three-phase connection of the generator to remove the third harmonic.

Appling this connection scheme of coils to the iron-core and air-core stators, the no-load voltage trends are performed, as shown in Figure 13.
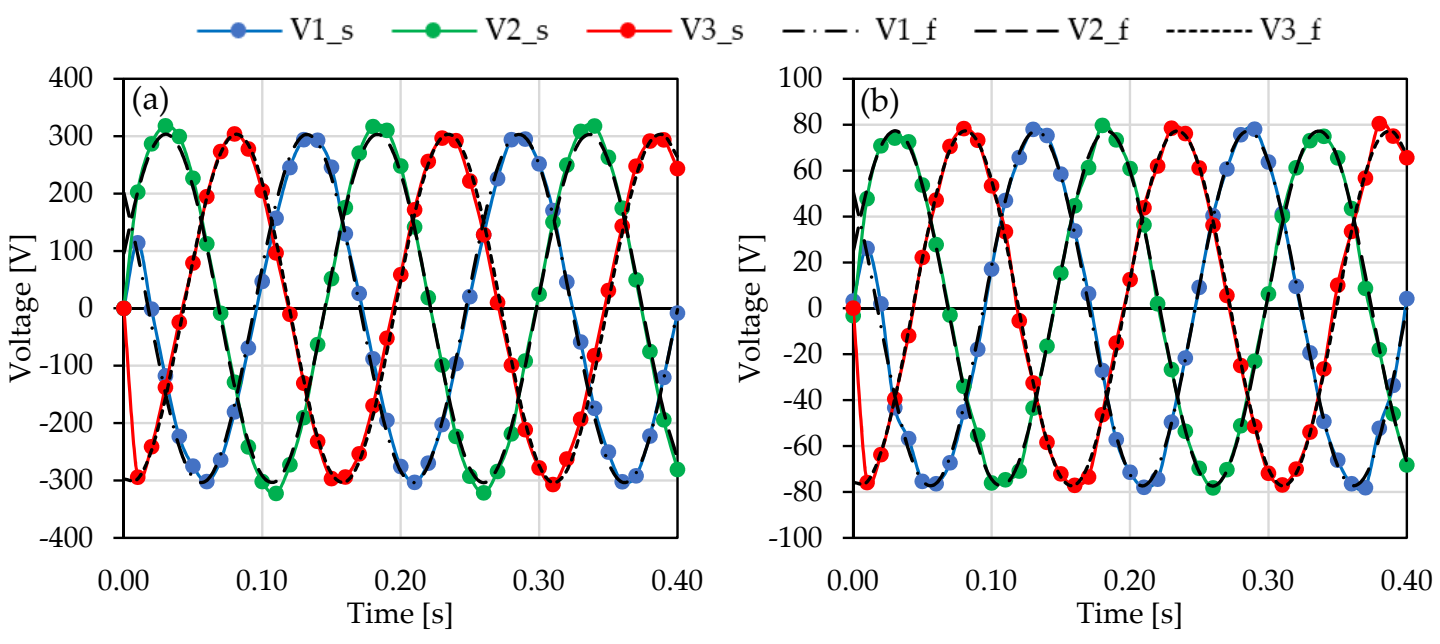

Figure 13. Comparison of no-load voltages, considering a different scheme of connection. (a) iron-core stator, (b) air-core stator. 
Both trends are approximated by a Fourier series, trimmed to the first harmonic, expressed by Equation (8):

$$
V_{i, f}(t)=A_{1} \sqrt{3} \sin \left[\omega t+\varphi_{1}-\frac{2}{3} \pi(i-1)-\frac{\pi}{6}\right]
$$

In detail, the connection introduced in Figure 12 converts the no-load voltage trends from the phase voltages to phase-to-phase voltages; therefore, the amplitude is increased by the factor $\sqrt{3}$ and the phase is reduced by the amount $\pi / 6$. In this configuration, the comparison of the prototype with the device without steel in the stator shows a reduction of the peak of voltages from 303.5 to $77.33 \mathrm{~V}$, with a ratio of 3.92:1.

The same ratio is obtained if the original connection of coils is kept, but not connecting the star center of the generator to the load. In this way, the homopolar components cannot be transferred to the load, among which the third harmonic is the most relevant.

Considering this configuration, the no-load voltage trends are evaluated, as reported in Figure 14. Both cases (iron-core and air-core) are modelled by Equation (8), considering the corresponding values of $A_{1}$ reported in Tables 2 and 3.

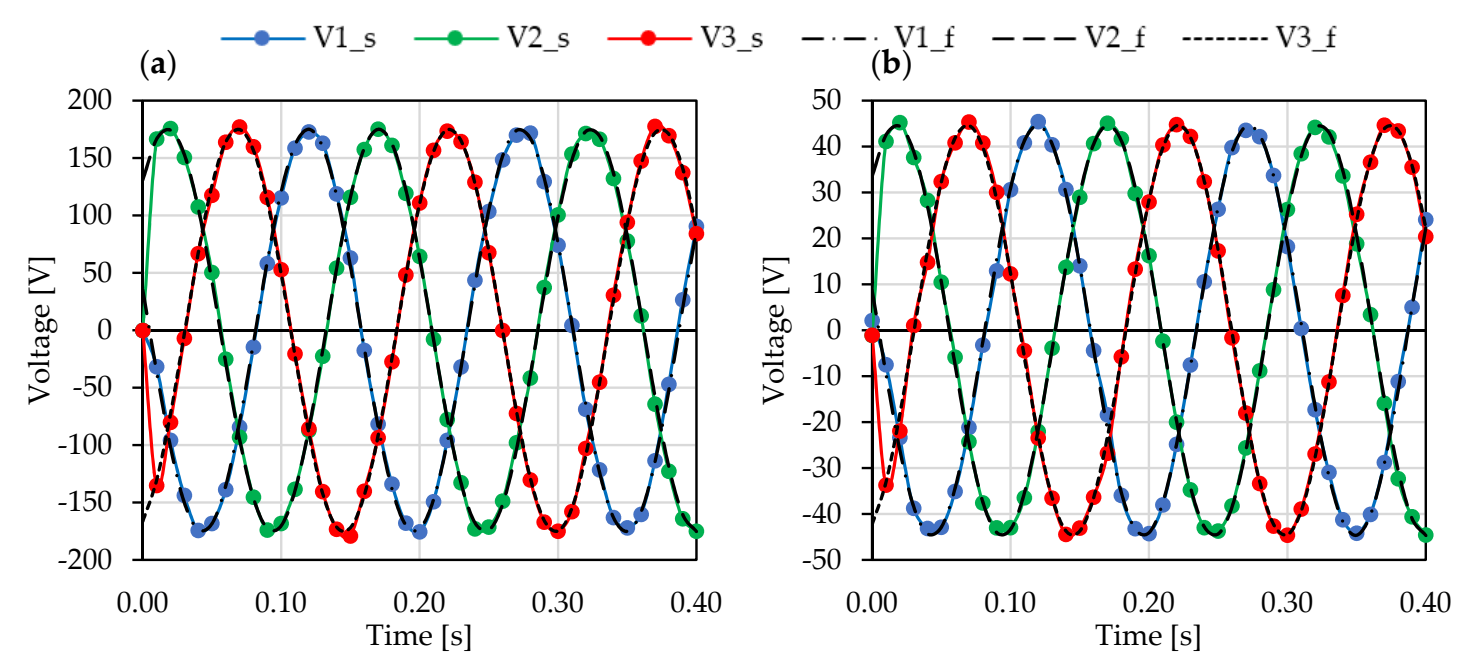

Figure 14. Comparison of no-load voltages obtained, not connecting the star center of the generator to load. (a) iron-core stator, (b) air-core stator.

\subsection{Cogging Force}

The cogging force is the second aspect investigated by authors, representing the magnetic force related to the interaction between the magnets and the iron stator. The phenomenon is related to two different origins:

- The alternance of tooth and slots in the iron stator;

- The entering and exiting of magnets through the stator region.

The first effect was minimized in previous studies [58], adopting the screwing of magnets. The second effect, also called "end effect", is related to the fact that the translator is longer than the stator. Being magnets installed on the translator, they are forced to enter and exit through the stator region.

This solution is preferred by the fact that all coils are uniformly excited by magnets; therefore, more connection schemes are usable in order to match the power output with the electrical load. However, the end effect is introduced in the system producing several negative aspects:

- Production of vibration and noise;

- Difficulty to start the system with low values of external force. 
The second aspect could be a real problem in sea wave applications, because the high value of the cogging force reduces the range of usable wave height for the electrical generation.

In this context, the replacement of steel stator represents a definitive solution, removing the material (iron) that is the origin of the phenomenon, as confirmed in Figure 15.

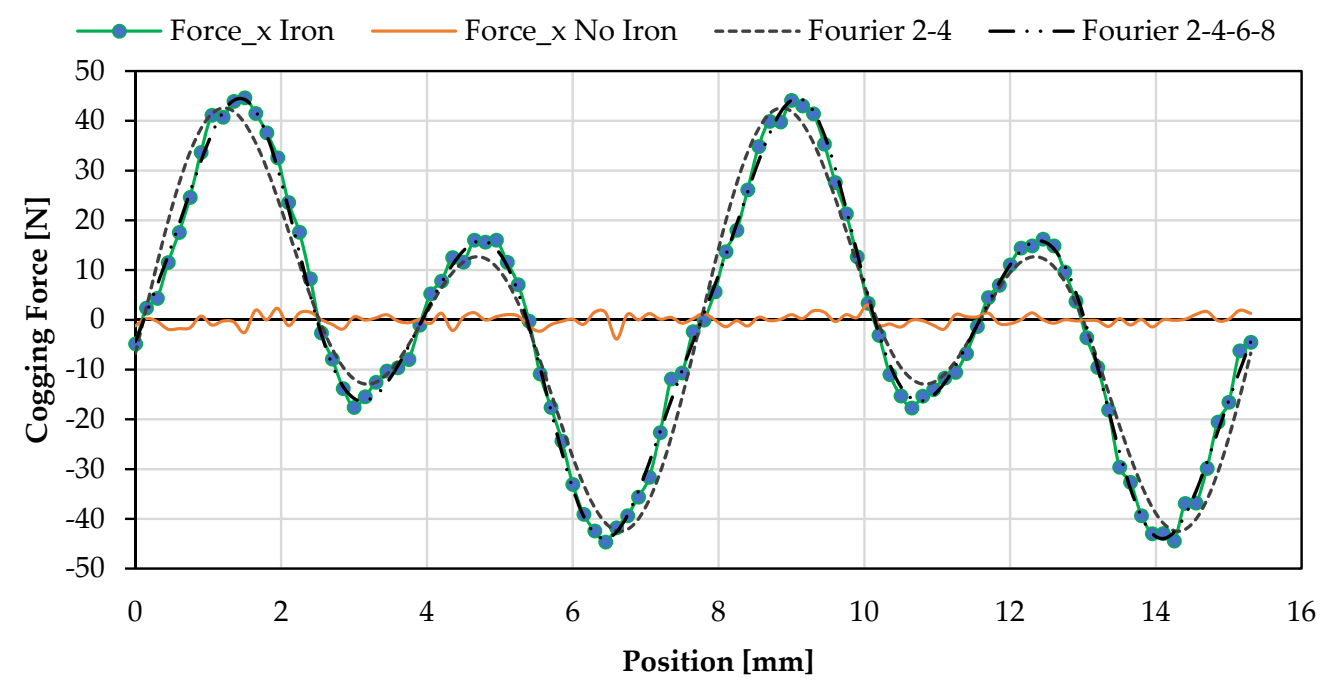

Figure 15. Comparison of the cogging force using a stator with steel and a non-magnetic material.

Concerning the prototype, the Fourier series was evaluated until the tenth harmonic, as reported in Table 4. According to the amplitudes reported below, the main terms are the second and the fourth harmonics, which are related to the "end effect". It is also possible to observe other secondary harmonics: the sixth and the eight ones, which are related to the alternance of tooth and slots along the stator. For these reasons, two Fourier approximations are reported in Figure 15. The first one considers only the main components (second and fourth harmonics), while the latter also includes the secondary components (sixth and eighth harmonics).

Table 4. Evaluation of Fourier terms until the tenth harmonic in the prototype case.

\begin{tabular}{ccc}
\hline Order & $\begin{array}{c}\text { Amplitude } \\
\boldsymbol{C}_{\boldsymbol{i}}[\mathrm{N}]\end{array}$ & $\begin{array}{c}\text { Phase } \\
\boldsymbol{\vartheta}_{\boldsymbol{i}}[\mathrm{rad}]\end{array}$ \\
\hline 0 & 0.064 & - \\
\hline 1 & 0.681 & 0.1892 \\
\hline 2 & 21.234 & -0.0864 \\
\hline 3 & 0.312 & -1.0273 \\
\hline 4 & 26.587 & -0.1833 \\
\hline 5 & 0.641 & 3.1637 \\
\hline 6 & 5.316 & 2.9119 \\
\hline 7 & 0.151 & 2.6296 \\
\hline 8 & 3.128 & 2.7715 \\
\hline 9 & 0.208 & 0.1307 \\
\hline 10 & 0.208 & 2.7913 \\
\hline
\end{tabular}

The Fourier approximation are evaluated according to Equation (9):

$$
\begin{gathered}
F_{24}(x)=C_{2} \sin \left(2 k x+\vartheta_{2}\right)+C_{4} \sin \left(4 k x+\vartheta_{4}\right) \\
F_{2468}(x)=F_{24}(x)+C_{6} \sin \left(6 k x+\vartheta_{6}\right)+C_{8} \sin \left(8 k x+\vartheta_{8}\right)
\end{gathered}
$$




\section{Conclusions}

The effects of iron replacement in the stator of linear permanent magnet generators are analyzed in the paper. The advantages and disadvantages, predictable qualitatively from the theory, are quantified by numerical simulations, using a specific tool. In detail, the benefits of the removal of steel, without changing the geometrical parameter of the device, can be synthetized as follows:

- Potential weight reduction of the machine;

- Complete removal of the cogging force, increasing the producibility of the electrical energy in sea wave application and drastically reducing the production of vibrations;

- Removal of third harmonic in no-load voltage generation, without changing the connection scheme in the machine.

Concerning the disadvantages, the removal of steel inside the stator produces a significant reduction of output voltages produced by the generator (5.25:1 in the first connection scheme, 3.92:1 in the other configurations). However, this effect can be attenuated by the introduction of limited changes in the device, as the increasing of the number of turns in the output coils, and increasing the total number of coils. Of course, further optimization should be applied in the linear generator. For example, the replacement of material used for coils (aluminum instead of copper) to further reduce its weight, or change the shape of stator, such as the width of stator teeth, or the number of turns for each coil, or the total number of coils. In any case, the presented study opens new scenarios for the development of linear generators for the exploitation of sea wave.

Author Contributions: Conceptualization and methodology: M.T., V.F., D.C.; software and validation: A.V., D.C.; resources and data curation, A.V., F.C.; writing-original draft preparation, D.C., F.C.; writing-review and editing, D.C., A.V., V.F., M.T., F.C.; supervision and project administration, M.T., V.F. All authors have read and agreed to the published version of the manuscript.

Funding: This research received no external funding.

Acknowledgments: This work is realized thanks to the technical support of Engosys Enterprise, by using informatic tools and developing mathematical models.

Conflicts of Interest: The authors declare no conflict of interest.

\section{References}

1. Owusu, P.A.; Asumadu-Sarkodie, S. A review of renewable energy sources, sustainability issues and climate change mitigation. Cogent Eng. 2016, 3, 1-14. [CrossRef]

2. Sierra, J.P.; Martín, C.; Mösso, C.; Mestres, M.; Jebbad, R. Wave energy potential along the Atlantic coast of Morocco. Renew. Energy 2016, 96, 20-32. [CrossRef]

3. IEA. Energy and Climate Change; IEA: Paris, France, 2015.

4. Enerdata Global Energy Statistical Yearbook. 2019. Available online: https://yearbook.enerdata.net/ (accessed on 26 December 2019).

5. International Renewable Energy Agency (IRENA). Renewable Capacity Statistics 2019; IRENA: Abu Dhabi, UAE, 2019.

6. Pelling, M.; Uitto, J.I. Small island developing states: Natural disaster vulnerability and global change. Glob. Environ. Chang. Part B Environ. Hazards 2001, 3, 49-62. [CrossRef]

7. Rusu, E.; Onea, F. Evaluation of the wind and wave energy along the Caspian Sea. Energy 2013, 50, 1-14. [CrossRef]

8. World Energy Council. World Energy Council. World Energy Resources. In Marine Energy 2016; World Energy Council: London, UK, 2016; p. 79.

9. Corsini, A.; Tortora, E.; Cima, E. Preliminary assessment of wave energy use in an off-grid minor island desalination plant. Energy Procedia 2015, 82, 789-796. [CrossRef]

10. Akar, S.; Akdoğan, D.A. Chapter 13-Environmental and Economic Impacts of Wave Energy: Some Public Policy Recommendations for Implementation in Turkey. In Handbook of Research on Green Economic Development Initiatives and Strategies; IGI Global: Hershey, PA, USA, 2016. 
11. Kalogirou, S.A. Solar Energy Engineering. Processes and Systems, 2nd ed.; Elsevier: Amsterdam, The Netherlands, 2014; ISBN 9780123972705.

12. Aderinto, T.; Li, H. Ocean Wave energy converters: Status and challenges. Energies 2018, 11, 1250. [CrossRef]

13. Mork, G.; Barstow, S.; Kabuth, A.; Pontes, M.T. Assessing the Global Wave Energy Potential. In Proceedings of the 29th International Conference on Ocean, Offshore and Arctic Engineering, ASME, Shanghai, China, 6-11 June 2010; Volume 3, pp. 447-454.

14. Liberti, L.; Carillo, A.; Sannino, G. Wave energy resource assessment in the Mediterranean, the Italian perspective. Renew. Energy 2013, 50, 938-949. [CrossRef]

15. De Falcão, A.F.O. Wave energy utilization: A review of the technologies. Renew. Sustain. Energy Rev. 2010, 14, 899-918. [CrossRef]

16. Hong, Y.; Waters, R.; Boström, C.; Eriksson, M.; Engström, J.; Leijon, M. Review on electrical control strategies for wave energy converting systems. Renew. Sustain. Energy Rev. 2014, 31, 329-342. [CrossRef]

17. Vannucchi, V.; Cappietti, L. Wave Energy Assessment and Performance Estimation of State of the Art Wave Energy Converters in Italian Hotspots. Sustainability 2016, 8, 1300. [CrossRef]

18. Van Rij, J.; Yu, Y.H.; Guo, Y.; Coe, R.G. A wave energy converter design load case study. J. Mar. Sci. Eng. 2019, 7, 250. [CrossRef]

19. Heras, P.; Thomas, S.; Kramer, M.; Kofoed, J.P. Numerical and Experimental Modelling of a Wave Energy Converter Pitching in Close Proximity to a Fixed Structure. J. Mar. Sci. Eng. 2019, 7, 218. [CrossRef]

20. Babarit, A.; Wendt, F.; Yu, Y.H.; Weber, J. Investigation on the energy absorption performance of a fixed-bottom pressure-differential wave energy converter. Appl. Ocean Res. 2017, 65, 90-101. [CrossRef]

21. Palma, G.; Formentin, S.M.; Zanuttigh, B.; Contestabile, P.; Vicinanza, D. Numerical simulations of the hydraulic performance of a breakwater-integrated overtopping wave energy converter. J. Mar. Sci. Eng. 2019, 7, 38. [CrossRef]

22. Poguluri, S.K.; Cho, I.H.; Bae, Y.H. A study of the hydrodynamic performance of a pitch-type wave energy converter-rotor. Energies 2019, 12, 842. [CrossRef]

23. Ji, C.Y.; GUO, Y.C.; Cui, J.; Yuan, Z.M.; Ma, X.J. 3D experimental study on a cylindrical floating breakwater system. Ocean Eng. 2016, 125, 38-50. [CrossRef]

24. Rusu, E.; Guedes Soares, C. Coastal impact induced by a Pelamis wave farm operating in the Portuguese nearshore. Renew. Energy 2013, 58, 34-49. [CrossRef]

25. Kurupath, V.; Ekst, R.; Leijon, M. Optimal Constant DC Link Voltage Operation of aWave Energy Converter. Energies 2013, 6, 1993-2006. [CrossRef]

26. Wacher, A.; Neilsen, K. Mathematical and Numerical Modeling of the AquaBuOY Wave Energy Converter. Math. Case Stud. J. 2010, 2, 16-33.

27. Polinder, H.; Damen, M.E.C.; Gardner, F. Linear PM Generator System for Wave Energy Conversion in the AWS. IEEE Trans. Energy Convers. 2004, 19, 583-589. [CrossRef]

28. Bozzi, S.; Archetti, R.; Passoni, G. Wave electricity production in Italian offshore: A preliminary investigation. Renew. Energy 2014, 62, 407-416. [CrossRef]

29. Colucci, A.; Boscaino, V.; Cipriani, G.; Curto, D.; Di Dio, V.; Franzitta, V.; Trapanese, M.; Viola, A. An inertial system for the production of electricity and hydrogen from sea wave energy. In Proceedings of the OCEANS 2015-MTS/IEEE, Washington, DC, USA, 19-22 October 2015; pp. 1-10.

30. Raimondi, F.M.; Milone, D.; Curto, D. An innovative mechanical motion converter for sea wave applications. In Proceedings of the 2018 Thirteenth International Conference on Ecological Vehicles and Renewable Energies (EVER) IEEE, Monte-Carlo, Monaco, 10-12 April 2018; pp. 1-6.

31. Franzitta, V.; Curto, D. Sustainability of the Renewable Energy Extraction Close to the Mediterranean Islands. Energies 2017, 10, 283. [CrossRef]

32. Atallah, K.; Zhu, Z.Q.; Howe, D. Armature reaction field and winding inductances of slotless permanent-magnet brushless machines. IEEE Trans. Magn. 1998, 34, 3737-3744. [CrossRef]

33. Abdel-Razek, A.; Coulomb, J.; Feliachi, M.; Sabonnadiere, J. The calculation of electromagnetic torque in saturated electric machines within combined numerical and analytical solutions of the field equations. IEEE Trans. Magn. 1981, 17, 3250-3252. [CrossRef]

34. Xia, T.; Yu, H.; Shi, Z.; Guo, R. Comparative Analysis and Experimental Verification of a Linear Tubular Generator for Wave Energy Conversion. Energies 2018, 11, 1707. [CrossRef] 
35. Farrok, O.; Islam, M.R.; Sheikh, M.R.I.; Guo, Y.; Zhu, J.G. A Split Translator Secondary Stator Permanent Magnet Linear Generator for Oceanic Wave Energy Conversion. IEEE Trans. Ind. Electron. 2018, 65, 7600-7608. [CrossRef]

36. Erselcan, İ.Ö.; Kükner, A. A Review of Power Take-Off Systems Employed in Wave Energy Converters. J. Nav. Sci. Eng. 2014, 10, 32-44.

37. Penalba, M.; Ringwood, J.V. A review of wave-to-wire models for wave energy converters. Energies 2016, 9, 506. [CrossRef]

38. Li, B.; Macpherson, D.E.; Shek, J.K.H. Direct drive wave energy converter control in irregular waves. In Proceedings of the IET Conference on Renewable Power Generation (RPG 2011) IET, Edinburgh, UK, 6-8 September 2011; p. 64.

39. Poullikkas, A. Technology Prospects of Wave Power Systems. Electron. J. Energy Environ. 2014, 2, 47-69.

40. Arof, H.; Nor, W.; Nor, K.M. Linear generator: Design and simulation. In Proceedings of the National Power Engineering Conference IEEE, Bangi, Malaysia, 15-16 December 2003; pp. 306-311.

41. Faiz, J.; Nematsaberi, A. Linear electrical generator topologies for direct-drive marine wave energy conversionan overview. IET Renew. Power Gener. 2017, 11, 1163-1176. [CrossRef]

42. Boldea, I.; Nasar, S.A. Linear Electric Actuators and Generators, 1st ed.; Cambridge University Press: Cambridge, UK, 1997; ISBN 9780521480178.

43. Rao, K.S.R.; Sunderan, T.; Ref, M. Performance and design optimization of two model based wave energy permanent magnet linear generators. Renew. Energy 2017, 101, 196-203. [CrossRef]

44. Zhang, G.; Yu, W.; Hua, W.; Cao, R.; Qiu, H.; Guo, A. The Design and Optimization of an Interior, Permanent Magnet Synchronous Machine Applied in an Electric Traction Vehicle Requiring a Low Torque Ripple. Appl. Sci. 2019, 9, 3634. [CrossRef]

45. García-Gracia, M.; Jiménez Romero, Á.; Herrero Ciudad, J.; Martín Arroyo, S. Cogging Torque Reduction Based on a New Pre-Slot Technique for a Small Wind Generator. Energies 2018, 11, 3219. [CrossRef]

46. Arehpanahi, M.; Kashe, H. Cogging torque reduction of Interior Permanent Magnet Synchronous Motor (IPMSM). Sci. Iran. 2018, 25, 1471-1477. [CrossRef]

47. Islam, M.S.; Mir, S.; Sebastian, T. Issues in Reducing the Cogging Torque of Mass-Produced Permanent-Magnet Brushless DC Motor. IEEE Trans. Ind. Appl. 2004, 40, 813-820. [CrossRef]

48. Awah, C.C.; Okoro, O.I.; Chikuni, E. Cogging torque and torque ripple analysis of permanent magnet flux-switching machine having two stators. Arch. Electr. Eng. 2019, 68, 115-133.

49. Shabani, M.A.; Milimonfared, J.; Taghipour, S. Cogging force mitigation of tubular permanent magnet machines with magnet dividing. In Proceedings of the 2007 International Conference on Electrical Machines and Systems (ICEMS), Seoul, Korea, 8-11 October 2007; pp. 810-814.

50. Wang, Q.; Zhao, B.; Zou, J.; Li, Y. Minimization of cogging force in fractional-slot permanent magnet linear motors with double-layer concentrated windings. Energies 2016, 9, 918. [CrossRef]

51. Zhou, S.; Yu, H.; Hu, M.; Jiang, C.; Hao, L. Reduction of cogging force in a linear flux-switching permanent-magnet brushless AC machine for direct-drive applications. IEEE Trans. Magn. 2011, 47, 3252-3255. [CrossRef]

52. Huang, W.; Shi, C.; Xue, Y.; Song, G.; Ling, Y. Optimal design of Permanent Magnet Linear Motor for reducing cogging force. In Proceedings of the 2014 IEEE Conference and Expo Transportation Electrification Asia-Pacific (ITEC Asia-Pacific), Beijing, China, 31 August-3 September 2014; pp. 1-4.

53. Franzitta, V.; Catrini, P.; Curto, D. Wave Energy Assessment along Sicilian Coastline, Based on DEIM Point Absorber. Energies 2017, 10, 376. [CrossRef]

54. Trapanese, M.; Boscaino, V.; Cipriani, G.; Curto, D.; Di Dio, V.; Franzitta, V. A Permanent Magnet Linear Generator for the Enhancement of the Reliability of a Wave Energy Conversion System. IEEE Trans. Ind. Electron. 2018, 0046, 1. [CrossRef]

55. Curto, D. Ottimizzazione Delle Performances Energetiche di un innovativo Generatore di Energia Elettrica da Moto Ondoso; Gruppo Editoriale L'Espresso: Rome, Italia, 2014.

56. Supermagnete. Available online: https://www.supermagnete.it/eng/data_sheet_Q-60-30-15-N.pdf (accessed on 3 February 2020). 
57. Monk, P. Finite Element Methods for Maxwell's Equations; Oxford University Press: Oxford, UK, 2003; ISBN 9780198508885.

58. Trapanese, M.; Cipriani, G.; Curto, D.; Di Dio, V.; Franzitta, V. Optimization of cogging force in a linear permanent magnet generator for the conversion of sea waves energy. In Proceedings of the 2015 IEEE International Electric Machines \& Drives Conference (IEMDC) IEEE, Coeur d'Alene, ID, USA, 10-13 May 2015; pp. 769-773.

(c)

(C) 2020 by the authors. Licensee MDPI, Basel, Switzerland. This article is an open access article distributed under the terms and conditions of the Creative Commons Attribution (CC BY) license (http://creativecommons.org/licenses/by/4.0/). 